\title{
Interactive comment on "Detecting layer height of smoke aerosols over vegetated land and water surfaces via oxygen absorption bands: Hourly results from EPIC/DSCOVR satellite in deep space” by Xiaoguang Xu et al.
}

Xiaoguang Xu et al.

jun-wang-1@uiowa.edu

Received and published: 7 May 2019

Thanks for the review. Please see item-by-item replies in the pdf attached.

Please also note the supplement to this comment:

https://www.atmos-meas-tech-discuss.net/amt-2018-414/amt-2018-414-AC1-

Interactive comment on Atmos. Meas. Tech. Discuss., doi:10.5194/amt-2018-414, 2018. 